$\Gamma$ идраденит суппуративный: современные представления о патогенезе, терапии и успешный опыт лечения адалимумабом

Хобейш М. М., Шустов Д. В., Соколовский Е. В.

Первый Санкт-Петербургский государственный медицинский университет им. акад. И. П. Павлова Минздрава России 197022, Российская Федерация, г. Санкт-Петербург, ул. Льва Толстого, д. 6/8, корп. 4

Гидраденит суппуративный (ГС) - хроническое воспалительное кожное заболевание, поражающее преимущественно участки расположения апокриновых желез; характеризующееся рецидивирующими болезненными узлами, абсцессами, приводящими к образованию свищей и рубцеванию. Современные представления о патогенезе ГС позволяют рассматривать его как разновидность инверсных акне, так как механизм развития ГС и инверсных акне не различается. Детальные исследования пациентов с ГС, проведенные в последние годы, дали возможность ряду авторов предположить, что ГС является системным хроническим иммуноопосредованным прогрессирующим заболеванием. Определена ключевая роль провоспалительного цитокина фрактора некроза опухоли $\alpha$ (ФНО- $\alpha)$ в развитии воспалительного процесса при ГС. Повышенные уровни ФНО- $\alpha$ обнаружены в крови и в очагах поражения ГС, причем определяется положительная корреляция уровня ФНО- $\alpha$ с тяжестью болезни. В настоящее время в качестве терапии 1-й линии при отсутствии адекватного ответа на стандартную системную терапию в случае активного ГС средней или тяжелой степени тяжести рекомендовано лечение блокатором ФНО- $\alpha$ - адалимумабом, единственным на сегодняшний день генно-инженерным биологическим препаратом, одобренным для лечения ГС/инверсных акне в мире и в России. Представленный клинический случай подтверждает тот факт, что для пациентов с ГС очень важно максимально быстрое определение правильного диагноза и назначение рационального лечения в соответствии с разработанными рекомендациями. Ошибочные диагнозы, неадекватная терапия (хирургическое лечение, короткие курсы приема антибиотиков и т.д.) способствуют прогрессированию заболевания, появлению общих симптомов за счет присоединения вторичной инфекции и повышению общей интоксикации, ограничению работоспособности, возникновению стойких и грубых рубцов, десрормаций пораженных участков кожи. Наш клинический случай применения адалимумаба $\left(\right.$ Хммиры $\left.{ }^{\circledR}\right)$ у пациента с крайне тяжелой формой ГС показал, что лечение этим препаратом может быть эфрфективным и хорошо переносимым.

Ключевые слова: суппуративный гидраденит, инверсные акне, патогенез, системная терапия, адалимумаб

Конфрликт интересов: авторы заявляют об отсутствии потенциального конфоликта интересов, требующего раскрытия в данной статье.

Для цитирования: Хобейш М. М., Шустов Д. В., Соколовский Е. В. Гидраденит суппуративный: современные представления о патогенезе, терапии и успешный опыт лечения адалимумабом. Вестник дерматологии и венерологии. 2017;(5):70-81. DOI: 10.25208/0042-4609-2017-93-5-70-81 


\title{
- idradenitis Suppurativa: Modern Concepts of Pathogenesis and Therapy; Successful Experience of Adalimumab Therapy
}

\author{
Marianna M. Khobeish, Denis V. Shustov, Evgeny V. Sokolovsky
}

Academician I. P. Pavlov First St. Petersburg State Medical University of the Ministry of Health of Russian Federation L'va Tolstogo str., 6/8, bldg 4, St. Petersburg, 197022, Russian Federation

Hidradenitis suppurativa (HS) is a chronic inflammatory skin disease that mainly affects the sites of the apocrine glands; HS is characterised by relapsing painful knots and abscesses, leading to the formation of fistulas and scarring. Modern ideas about the pathogenesis of HS allow us to consider it as a kind of inverse acne, since the mechanism of development of HS and inverse acne does not differ. Detailed studies of patients with HS in recent years have provided the basis for several authors to suggest that HS is a systemic, chronic, immune-mediated progressive disease. The key role of the proinflammatory cytokine tumor necrosis factor $\alpha$ (TNF- $\alpha$ ) in the development of the inflammatory process during HS was determined. Elevated TNF- $\alpha$ levels are found in the blood and HS lesions, having a positive correlation of the TNF- $\alpha$ level with the severity of the disease. At the present time, the treatment with a TNF- $\alpha$ blocker, adalimumab (the only one genetically engineered biological preparation approved for treatment of HS/inverse acne in the world and in Russia), is recommended as a first-line therapy in the absence of an adequate response to standard systemic therapy in the case of active HS of moderate or utmost severity. The presented clinical case confirms the fact that for HS patients it is very important to determine the correct diagnosis as quickly as possible and to prescribe the appropriate treatment according to the developed recommendations. Erroneous diagnoses, inadequate therapy (surgical treatment, short courses of antibiotics, etc.) contribute to the progression of the disease, to the appearance of common symptoms due to the attachment of secondary infection and increase in general intoxication, to limited working capacity, to the emergence of persistent and gross scars, as well as to the deformations of affected skin. Our clinical case of adalimumab (Humira) treatment of a patient with an extremely severe HS form demonstrated that the application of this medication can be effective and well tolerated.

Keywords: suppurative hidradenitis, inverse acne, pathogenesis, systemic therapy, adalimumab

Conflict of interest: the authors state that there is no potential conflict of interest requiring disclosure in this article.

For citation: Khobeish M. M., Shustov D. V., Sokolovsky E. V. Hidradenitis Suppurativa: Modern Concepts of Pathogenesis and Therapy; Successful Experience of Adalimumab Therapy. Vestnik Dermatologii i Venerologii. 2017;(5):70-81. DOI: 10.25208/0042-4609-2017-93-5-70-81 
Гидраденит

суппуративный

(ГС

(hidradenitis suppurativa, по международной классификации болезней 10-го пересмотра - L73.2, гидраденит гнойный) - хроническое воспалительное кожное заболевание, поражающее преимущественно участки расположения апокриновых желез; характеризующееся рецидивирующими болезненными узлами, абсцессами, приводящими к образованию свищей и рубцеванию $[1,2]$. Очаги кожного поражения обычно локализуются в подмышечных, пахово-бедренных, ягодичных областях, в области молочных желез и наружных половых органов.

Современные представления о патогенезе ГС позволяют рассматривать его как разновидность инверсных акне (acne inversa), так как механизм развития ГС и инверсных акне не различается. Воспалительный процесс при ГС исходит не из апокриновых потовых желез, а из расположенных также перифолликулярно сальных желез и является следствием первичного гиперкератоза в терминальных волосяных фолликулах с их окклюзией при гиперсекреции сальных желез [3]. В последующем присоединяется бактериальное инфрицирование резидентной микробной фрлорой, развивается иммунный ответ (перифолликулярное лимфогистиоцитарное воспаление), что в итоге приводит к развитию клинических проявлений ГС.

Детальные исследования пациентов с ГС, проведенные в последние годы, дали возможность ряду авторов предположить, что ГС является системным хроническим иммуноопосредованным прогрессирующим заболеванием [1, 4-6]. Известно, что в посевах при ГС обнаруживаются в основном непатогенные бактерии, и вероятно, данное заболевание развивается в результате неадекватного иммунного ответа ввиду дисрегуляции как врожденного, так и приобретенного иммунитета у пациентов с ГС на бактерии-комменсалы [7]. Бактерии принимают участие В инициации иммунного ответа при ГС, но они не являются его причиной. Фолликулярная окклюзия - провоцирующий фрактор развития вторичной инфекции. Подобный механизм развития наблюдается при болезни Крона [8]. Для обоих заболеваний в очагах характерна инфильтрация иммунными клетками, в частности Th1- и Th17-лимфоцитами. При ГС в процесс дополнительно вовлекаются

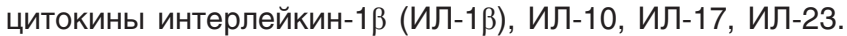
Провоспалительный цитокин фрактор некроза опухоли $\alpha$ (ФНО- $\alpha$ ) играет ключевую роль в развитии воспалительного процесса при ГС [9]. Повышенные уровни ФНО- $\alpha$ обнаружены в крови и в очагах поражения ГС [5], причем определяется положительная корреляция уровня ФНО- $\alpha$ с тяжестью болезни [10]. ФНО- $\alpha$ увеличивает число молекул адгезии, что ведет к миграции лейкоцитов [11] и способствует пролиферации эпителия, приводя к окклюзии фолликулов и риску их разрывов $[1,12]$. Доказана роль ФНО- $\alpha$ в развитии хронического воспаления: поврежденные клетки сальной железы инициируют формирование абсцесса; ФНО- $\alpha$ и другие провоспалительные цитокины провоцируют изменения, вызывающие образование и пролиферацию эпителизированных свищевых ходов [1, 12]; «биопленка» из бактерий, находящихся в поврежденных клетках и свищевых ходах, обеспечивает хронизацию воспаления [1, 12], риск распространения воспаления и развития обострений заболевания [13].

Таким образом, окончательно этиология ГС еще не доказана. ГС представляет собой многофракториальное заболевание, при котором генетические, иммунные, эндокринные и поведенческие фракторы играют ключевую роль. Исследования показали, что 30-40\% пациентов с ГС имели семейный анамнез [14, 15]. Курение сигарет, ожирение и избыточный вес являются триггерами в развитии ГС [16]. Он обычно развивается после полового созревания, чаще во 2-й или 3-й декаде жизни, с большей частотой у женщин. Распространенность ГС остается невыясненной. По данным некоторых исследований, это заболевание наблюдается примерно у $1 \%$ жителей Европы $[16,17]$, у 4\% среди молодых женщин [18]. Данные американских исследователей свидетельствуют о распространенности ГС от 0,05 до 0,20\% в общей популяции $[19,20]$.

Среднетяжелый и тяжелый ГС значительно снижает качество жизни пациентов. Такие проявления болезни, как выраженная боль, ограничение подвижности, свищевые ходы с отделяемым, имеющим неприятный запах, приводят к снижению самооценки, работоспособности, развитию депрессии и, как следствие, социальной изоляции больных [21-23].

Поскольку не существует специального патогномоничного теста для диагностики ГС, заболевание определяется по характерным клиническим проявлениям, типичным локализациям и рецидивирующему, хроническому течению. Поражение разных частей тела и неспецифрические симптомы заставляют пациентов обращаться к врачам различных специальностей (хирургам, инфекционистам, гинекологам, урологам, иммунологам и т.д.), которые в большинстве случаев принимают кожные поражения ГС за обычные абсцессы, в связи с чем постановка правильного диагноза ГС отсрочена. По данным одного из исследований, у 164 пациентов время до постановки диагноза ГС в среднем составило 7 лет $[4,24]$.

Традиционно считается, что ГС следует диагностировать на основании следующих клинических признаков:

- типичный характер поражения (глубоколежащий воспалительный узел и/или рубцы);

- типичная локализация (подмышечные и пахово-бедренные области), симметричность поражения;

- течение заболевания (хроническое, склонное к рецидивированию).

Подтверждают диагноз ГС положительные ответы на следующие вопросы [4]:

- «Имеются ли такие же симптомы в семье?»

- «Фурункулы появляются в одних и тех же местах?»

- «Курите ли Вы?»

- «Наблюдаются ли обострения перед менструацией?»

Также диагноз ГС подтверждают отрицательные ответы на следующие вопросы [4]:

- «Помогло ли лечение у терапевта?»

- «Фурункулы на коже хаотичные?»

- «Есть ли какая-либо инфекция?»

- «Сопровождаются ли фурункулы повышением температуры?»

Согласно Европейским рекомендациям по лечению гидраденита суппуративного/инверсных акне 2015 г. [25], диагноз ГС можно предположить при наличии характерной клинической картины: рецидивирующее воспаление (более 2 рецидивов в течение 6 мес); кожное поражение, представленное узлами, абсцессами, свищами и/или рубцами. Для постановки диагноза ГС важно наличие основных и дополнительных диагностических критериев заболевания [25]. К основным диагностическим критериям ГС относят следующие признаки [25]: вовлечение подмышечной, пахово-бедренной, ягодичной областей и молочных желез (у женщин); наличие узлов (с признаками вос- 
Таблица 1. Клиническая классификация ГС по Hurley (1989 г.)

\begin{tabular}{cl}
\hline Стадия & Клинические проявления \\
\hline I & Формирование одиночного или множественных абсцессов без свищей и рубцов \\
\hline II & $\begin{array}{l}\text { Рецидивирующие абсцессы с формированием свищей или рубцов, одиночные или множественные поражения на рас- } \\
\text { стоянии друг от друга }\end{array}$ \\
\hline III & $\begin{array}{l}\text { Дифффузне или близкое к дифффузному распространение воспаления или множественные сообщающиеся свищевые } \\
\text { ходы и абсцессы на всей области }\end{array}$
\end{tabular}

паления или без них), свищей (с признаками воспаления или без них), абсцессов, рубцов (атрофических, петлевидных, гипертрофических или линейных). Дополнительными критериями являются [25] наличие ГС в семейном анамнезе и данные микробиологического исследования (отсутствие патогенной флоры, присутствие нормальной микрофрлоры кожи).

Дифрференциальную диагностику, согласно Европейским рекомендациям по лечению гидраденита суппуративного/инверсных акне 2015 г., следует проводить со стафилококковой инфекцией; кожными проявлениями болезни Крона на фоне активной манифестации заболевания; простым абсцессом (обычно одиночным образованием); новообразованием, первичным или метастатическим (по клиническим или гистологическим признакам новообразования); венерической лимфогранулемой; актиномикозом кожи; скрофрулодермой [25].

Для оценки степени тяжести ГС в настоящее время применяется несколько оценочных систем. Одной из самых простых и широко применяемых является клиническая классификация ГС по Hurley [2, 12, 25-27] (табл. 1). В ряде случаев используется шкала оценки тяжести ГС по Sartorius $[4,28]$ (табл. 2). Существует также оценка степени тяжести заболевания по индексу PGA (Physician's Global Assessment - глобальная оценка врача) [29] (рис. 1).
Для оценки эффрективности терапии рекомендуется использовать шкалу клинического ответа на лечение гнойного гидраденита (HiSCR) [26, 29]. Шкала HiSCR дает возможность сравнить клиническую картину заболевания до начала терапии, в процессе ее проведения и по ее окончании. По данной шкале терапия считается эффрективной при соблюдении нескольких минимальных условий: количество абсцессов и воспалительных узлов уменьшилось не менее чем на $50 \%$ и количество свищей с отделяемым и абсцессов как минимум не увеличилось (рис. 2).

K сожалению, существующие в настоящее время подходы к лечению не основаны на достаточной доказательной клинической базе [25]. Широко используются антибиотики: топические препараты применяются на ограниченных участках при более легких фрормах заболевания, системные антибиотики - при наличии более тяжелых или распространенных поражений. Однако антибиотики при ГС направлены на борьбу со вторичной бактериальной инфекцией, и такая терапия носит симптоматический характер [25]. Терапия ретиноидами, глюкокортикостероидами, дапсоном, циклоспорином не всегда бывает достаточной при среднетяжелых и тяжелых фрормах ГС. Хирургическое лечение, лазерная терапия являются стандартными методами лечения ГС, однако они предполагают только локальное вмешательство,

Таблица 2. Шкала оценки тяжести ГС по Sartorius
Параметр
Оценка
3 балла за 1 локализацию:
- аксиллярная область
- паховые складки
- гениталии
- ягодицы
другие локализации


Рис. 1. Шкала оценки тяжести ГС по индексу PGA

PGA

Значение активности

\begin{tabular}{|c|c|}
\hline Чисто & $\begin{array}{l}0 \text { - абсцессы, } 0 \text { - свищи с отделяемым, } 0 \text { - узлы с признаками воспаления, } 0 \text { - узлы без признаков } \\
\text { воспаления }\end{array}$ \\
\hline
\end{tabular}

\begin{tabular}{|c|c|}
\hline Минимальная & 0 - абсцессы, 0 - свищи с отделяемым и 0 - узлы с признаками воспаления \\
\hline Легкая & $\begin{array}{l}1 \text { - абсцессы, } 0 \text { - свищи с отделяемым и <5-узлы с признаками воспаления } \\
\text { или } \\
2 \text { - абсцесс или свищ с отделяемым и } 0 \text { - узлы с признаками воспаления }\end{array}$ \\
\hline Умеренная & $\begin{array}{l}1 \text { - абсцессы, } 0 \text { - свищи с отделяемым и } \geq 5-\text { узлы с признаками воспаления } \\
\text { или } \\
2 \text { - абсцесс или свищ с отделяемым и } \geq 1-\text { узлы с признаками воспаления } \\
\text { или } \\
2-5 \text { - абсцессы или свищи с отделяемым или <10 - узлы с признаками воспаления }\end{array}$ \\
\hline Тяжелая & 2-5 - абсцессы или свищи с отделяемым и $\geq 10$ - узлы с признаками воспаления \\
\hline
\end{tabular}

Pис. 2. Оценка эффективности терапии по шкале HiSCR

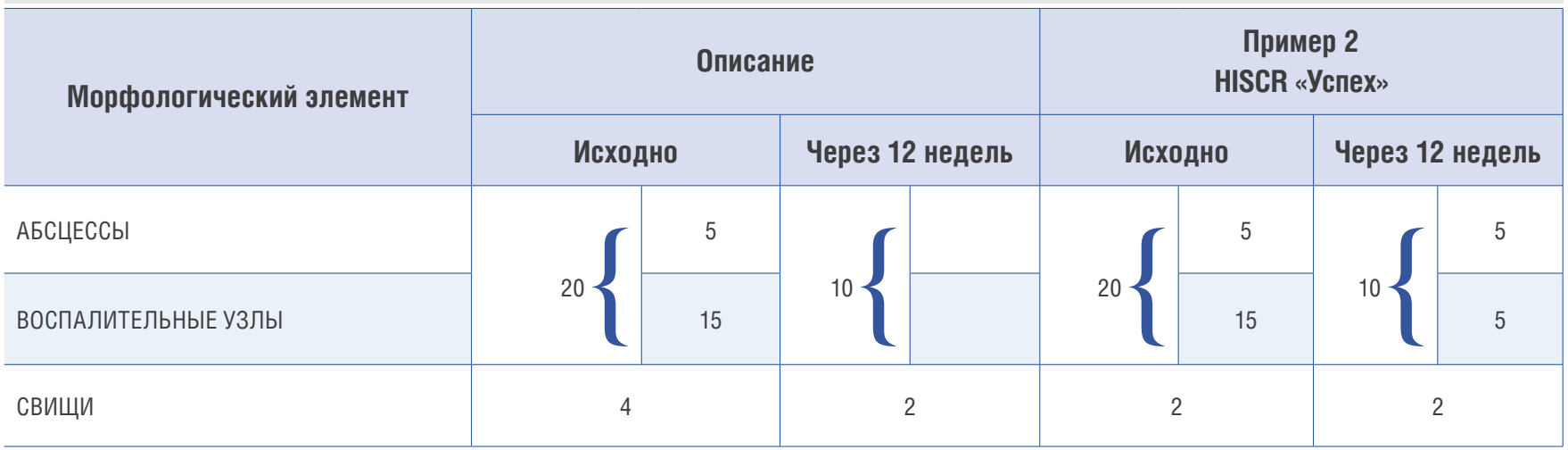

не устраняющее первопричину этого системного заболевания воспалительной этиологии [24, 30-32]. Несмотря на проведенное хирургическое или лазерное лечение, ГС может вновь рецидивировать, прогрессировать, захватывая новые области тела, особенно при тяжелом течении заболевания [24, 30].

Ввиду того, что существующие методы лечения ГС ограничены и часто недостаточно эфффективны, в последние годы для лечения умеренной и тяжелой форм ГС при отсутствии адекватного ответа на стандартную системную терапию применяются препараты из группы генно-инженерных биологических средств - моноклональные антитела к фактору некроза опухоли $\alpha$ (ФНО- $\alpha)$ и ингибиторы других интерлейкинов.

В 2016 г. был опубликован модифицированный алгоритм лечения ГС/инверсных акне, основанный на Европейском руководстве по лечению гидраденита суппуративного/инверсных акне 2015 г. [33] (рис. 3). Согласно этому алгоритму, для решения вопроса о тактике лечения необходимо учитывать стадию заболевания по Hurley, степень активности заболевания по Sartorius и индексу PGA, качество жизни пациента. Эфффективность прово- димой терапии следует объективно оценивать по индексу HiSCR.

Лекарственные препараты 1-й линии включают клиндамицин (местно), клиндамицин и рисрампицин (перорально), адалимумаб (подкожно), тетрациклин (перорально). В рамках медикаментозной терапии 2-й линии рекомендовано применять цинка глюконат, резорцинол, глюкокортикостероиды (для введения в очаги поражения, системно), инфрликсимаб (в настоящее время не зарегистрирован по показанию ГС), ацитретин. При неэффективности препаратов первых 2 линий назначаются препараты 3-й линии: колхицин, ботулотоксин, изотретиноин, дапсон и циклоспорин; а также терапия, корригирующая гормональный статус (антиандрогены). Адъювантная терапия и мероприятия при ГС предполагают купирование болевого синдрома, лечение вторичной инфекции, а также коррекцию веса и отказ от курения [33] (см. рис. 3).

В качестве терапии 1-й линии в случае активного ГС средней или тяжелой степени тяжести у взрослых пациентов при отсутствии адекватного ответа на стандартную системную терапию рекомендуется лечение блокатором ФНО- $\alpha$ - адалимумабом, единственным на сегодняшний 


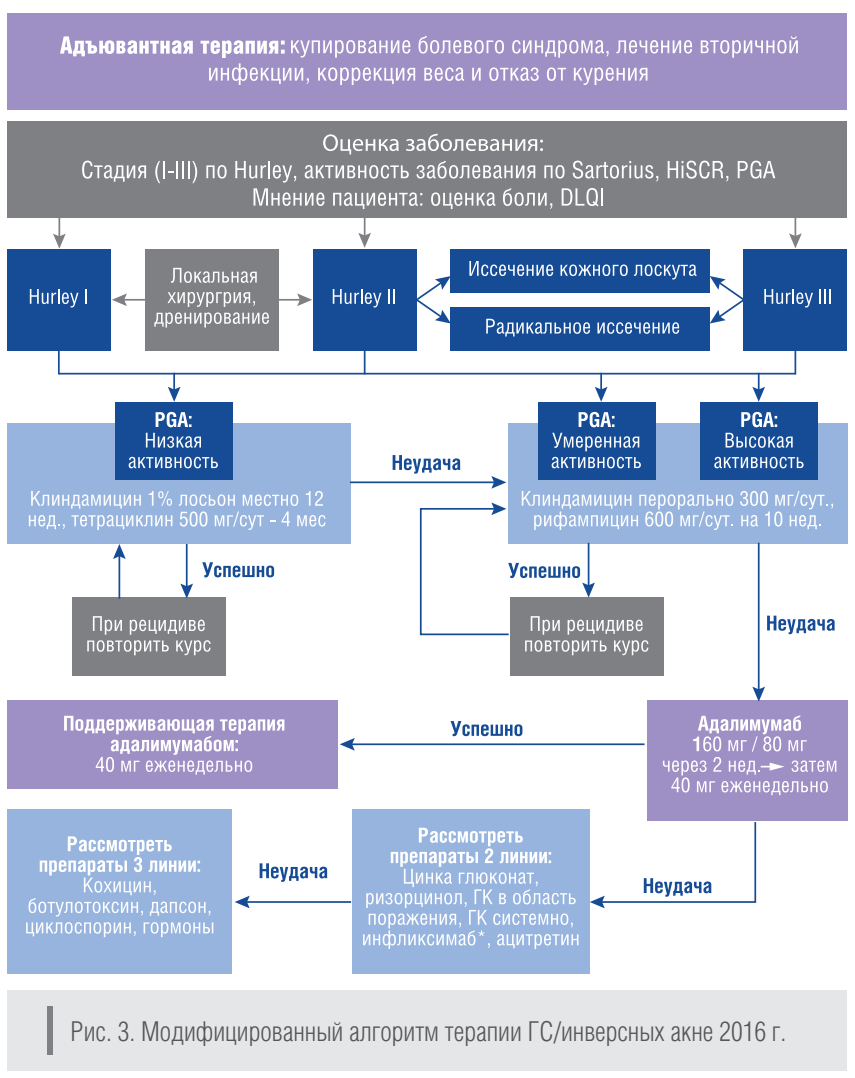

день генно-инженерным биологическим препаратом, одобренным FDA (Food and Drug Administration - Управление по санитарному надзору за качеством пищевых продуктов и медикаментов) для лечения ГС. В настоящее время накоплен убедительный позитивный международный опыт применения адалимумаба для лечения ГС средней или тяжелой степени тяжести [34-36].

В Российской Федерации адалимумаб $\left(\right.$ Хмира $\left.^{\circledR}\right)$ одобрен в 2016 г. для лечения активного гнойного гидраденита средней или тяжелой степени тяжести при отсутствии адекватного ответа на стандартную системную терапию у пациентов с 12 лет [37]. Рекомендованная схема назначения адалимумаба(Хумиры ${ }^{\circledR}$ ) для лечения среднетяжелого и тяжелого ГС заключается в следующем. Начальная доза адалимумаба 160 мг: по 40 мг 4 раза в день в течение 1-х суток или по 40 мг 2 раза в день в течение первых 2 сут. Продолжение терапии осуществляется на 15-й день лечения адалимумабом: вводится 80 мг (по 40 мг 2 раза в день). Следующее введение адалимумаба на 29-й день от начала терапии - 40 мг 1 раз в день. Далее, в качестве поддерживающей терапии, вводят по 40 мг адалимумаба 1 раз в неделю [33].

\section{Клинический случай}

Больной К., 38 лет, житель Красноярского края, инвалид II группы, неоднократно находился на стационарном лечении в клинике дерматовенерологии ПСПбГМУ им. акад. И. П. Павлова начиная с сентября 2012 г. Из анамнеза обращает на себя внимание, что больной курил в течение 15 лет по 2 пачки сигарет в день, последние 5 лет - по 1 пачке в день. До начала болезни имел повышенную массу тела. За 8 лет болезни похудел на 25 кг. Более 10 лет работал водителем большегрузных машин и часто бывал в длительных командировках. Семейный анамнез не отягощен.
Считает себя больным с 2008 г., когда впервые заметил болезненные высыпания на коже ягодичной области. К врачу по данному поводу не обращался, лечился самостоятельно. Через месяц количество высыпных элементов увеличилось, в связи с чем самостоятельно принимал антибактериальный препарат (группа макролидов) с временным положительным эффректом. Через 6 мес от начала заболевания впервые обратился к дерматологу в кожно-венерологический диспансер по месту жительства в г. Минусинске, где был поставлен диагноз «фрурункулез». Была рекомендована наружная терапия, эфрфект от которой был временным. Кожные поражения рецидивировали, отмечалось появление новых элементов (абсцессов, свищей). В марте 2009 г. больному был поставлен диагноз: «актиномикоз с поражением подмышечных областей, ягодиц, свищевая форма». В период с марта по сентябрь 2009 г. неоднократно получал антибактериальную терапию (полусинтетический пенициллин, комбинированный с ингибитором бета-лактамаз; антибиотик цефалоспоринового ряда), но заболевание прогрессировало.

В период с апреля по май 2009 г. находился на стационарном лечении в отделении гнойной хирургии Краевого гнойно-септического центра г. Красноярска с диагнозом: «актиномикоз с поражением подмышечных областей, правой ягодицы, свищевая фрорма». Поступил с наличием множества (около 30) свищей с гнойным отделяемым в обеих подмышечных областях и в области правой ягодицы. На фоне проводимой терапии (антибактериальный препарат (полусинтетический пенициллин, комбинированный с ингибитором бета-лактамаз), перевязки, фризиотерапевтическое лечение) состояние больного несколько улучшилось. Свищи в левой подмышечной области закрылись, в области правой ягодицы количество свищей уменьшилось до 4, в правой подмышечной области свищевой ход сохранялся.

В сентябре 2009 г. находился на стационарном лечении в кожной клинике СибГМУ (г. Томск), где был поставлен диагноз: «глубокая пиодермия, осложненная фрлегмоной правой ягодицы». В октябре 2009 г. - повторная госпитализация в госпитальную хирургическую клинику СибГМУ (г. Томск) с диагнозом: «Глубокая пиодермия обеих ягодиц и медиальной поверхности бедра, промежности, осложненная глубокой фрлегмоной. Сопутствующий диагноз: двусторонний гидроцеле». По данным проведенного бактериологического исследования от 12.10.2009 в отделяемом свищевых ходов патогенной микрофрлоры не обнаружено. Дважды в период с февраля по март 2011 г. находился на стационарном лечении в госпитальной хирургической клинике СибГМУ с диагнозом: «Глубокое гнойное поражение кожи неуточненной этиологии поясничной области, ягодичной, подмышечных областей, промежности. Метициллин-резистентный золотистый стафилококк?». Проведенное трижды исследование крови на стерильность в 2011 г. показало отсутствие микрофрлоры. По заключению фристулографического исследования от 2011 г.: сложноразветвленные свищи крестцово-копчиковой области с переходом на левое бедро, ягодицы справа; свищевые ходы поднимаются до III крестцового позвонка; сообщений с прямой кишкой не выявлено; выявляются небольшие дефекты наполнения в просвете свищевых ходов, обусловленные грануляционно-рубцовыми тканями. В клинике СибГМУ в 2011 г. получал антибактериальную терапию (препарат группы 


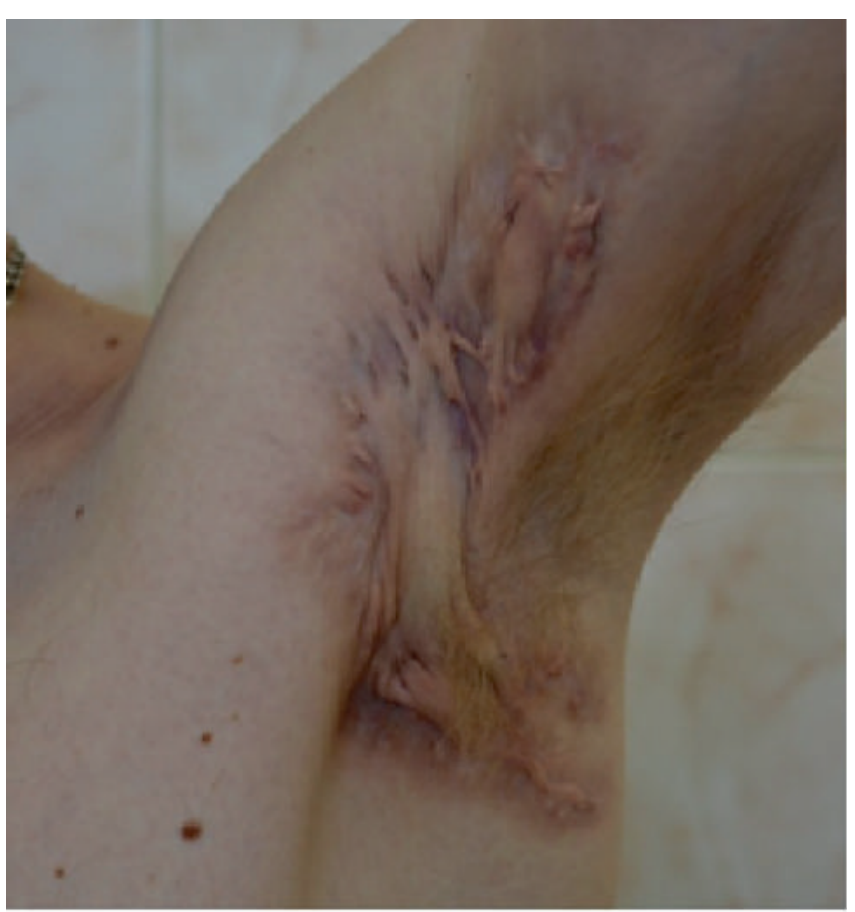

Рис. 4. Пациент К. Проявления ГС в подмышечной области

(воспалительные узлы, гипертрофические и келоидные рубцы)

оксазолидинонов) курсом 14 дней. Через 6 мес - повторный курс приема этого же антибактериального препарата с положительным эфффектом (ремиссия 1,5 мес).

В сентябре 2012 г. больной поступил в клинику дерматовенерологии ПСПбГМУ им. акад. И. П. Павлова, где впервые был поставлен диагноз: «Инверсные акне. Гнойный (суппуративный) гидраденит» (рис. 4-8). В кли-

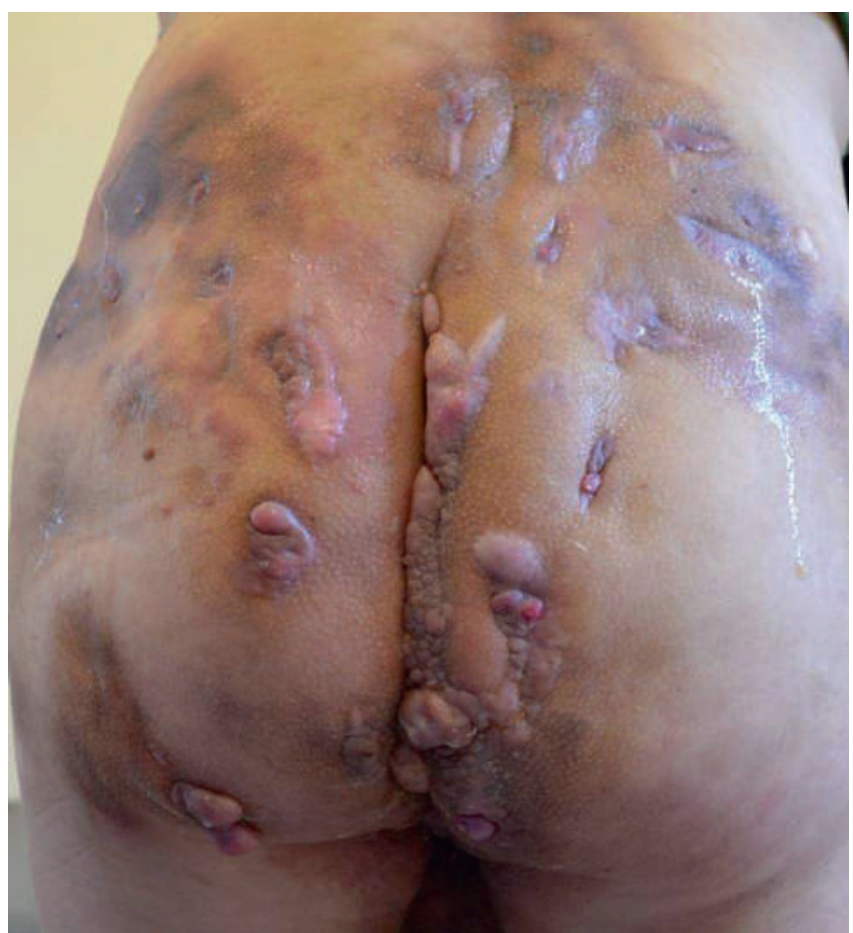

Рис. 5. Пациент К. Проявления ГС на коже поясничной и ягодичной областей (воспалительные узлы, абсцессы, выходные отверстия свищевых ходов, из которых выделяется жидкое гнойно-кровянистое содержимое, келоидные рубцы) нике проводилась активная антибактериальная терапия (последовательно: фрторхинолон; трициклический гликопептид; полусинтетический пенициллин, комбинированный с ингибитором бета-лактамаз), начата терапия системными ретиноидами - производными изотретиноина (роаккутан 40 мг/сут). На фоне проводимого лечения отмечалась положительная динамика: уменьшение количества узлов и абсцессов, гиперемии и болезненности в области воспалительных инфрильтратов поясничной, ягодичной областей и промежности; уменьшение количества отделяемого из свищевых ходов, улучшение общего самочувствия, снижение температуры, нормализация лабораторных параметров (снижение скорости оседания эритроцитов (СОЭ)).

В июне 2013 г. в связи с обострением основного заболевания пациент был повторно госпитализирован в клинику дерматовенерологии ПСПбГМУ им. акад. И. П. Павлова, где получал антибактериальную тера-

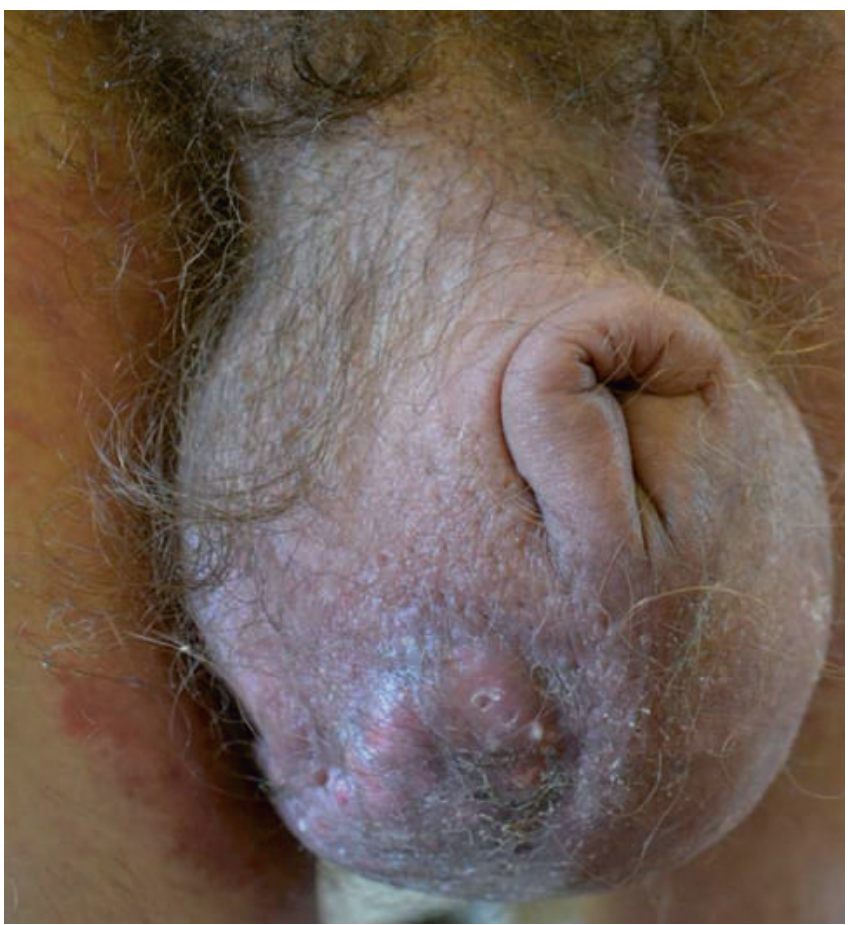

Рис. 6. Пациент К. Проявления ГС в пахово-мошоночной области (воспалительные узлы, абсцессы, гипертрофические рубцы).

Двусторонний гидроцеле осумкованный

пию (антибиотик цефралоспоринового ряда внутривенно капельно в течение 10 дней), продолжал назначенную в 2012 г. терапию системными ретиноидами (доза была увеличена до 50 мг/сут). Был выписан с положительной динамикой в течении основного заболевания. Однако с сентября 2013 г. в связи с повышением температуры тела в вечернее время до $38^{\circ} \mathrm{C}$ и увеличением количества узлов, абсцессов, отделяемого из свищевых ходов был вновь госпитализирован в клинику дерматовенерологии ПСПбГМУ им. акад. И. П. Павлова, где на фроне терапии системными ретиноидами, антибактериальной терапии (антибиотик цефалоспоринового ряда внутривенно капельно, 10 дней) осуществлялось внутриочаговое введение бетаметазона. Был выписан с улучшением общего состояния, нормализацией температуры тела и положительной динамикой в течении кожного процесса в виде уменьшения количества абсцессов в поясничной, 
ягодичной областях и промежности, уменьшения количества отделяемого из свищевых ходов.

В декабре 2013 г. развился рецидив заболевания, появились новые узлы, абсцедирующие элементы, свищи. В фреврале 2014 г. в частной клинике г. Минусинска были выполнены инъекции триамцинолона ацетонида в очаги поражения, но положительный эффект был временным, отмечалось дальнейшее прогрессирование заболевания.

При повторных госпитализациях в клинику дерматовенерологии ПСПбГМУ им. акад. И. П. Павлова продолжали антибактериальную терапию. Системные ретиноиды были отменены ввиду превышения курсовой дозы (более 250 мг/кг) и отсутствия эфффекта, а также развития нежелательных явлений (дислипидемия). Была назначена терапия метотрексатом (методжектом) подкожно в дозе 20 мг в неделю. На фоне терапии метотрексатом отмечалась некоторая положительная динамика. Но, со слов пациента, через 3 мес от начала терапии в связи с недостаточностью эффректа и плохой переносимостью препарата (диспепсические расстройства) пациент самостоятельно прекратил применение метотрексата.

K апрелю 2016 г. у больного отмечалось прогрессирование заболевания (появление новых узлов, абсцессов, свищей), значительно ухудшилось общее состояние (боль в области пораженных участков кожи, учащающиеся периоды значительного подъема температуры, ознобы, нарастающая слабость; снижение массы тела (за 8 лет болезни пациент похудел на 25 кг)), снизилось качество жизни (выраженная болезненность в очагах кожного поражения, нарушение сна, повышенная тревожность, депрессия), отмечалось стойкое изменение лабораторных параметров (лейкоцитоз, анемия, значительное повышение острофазовых показателей (СОЭ выше 45 мм/4, уровень С-реактивного белка (СРБ) более 80 мг/л). В связи с этим в очередной раз был госпитализирован в клинику дерматовенерологии ПСПбГМУ им. акад. И. П. Павлова. Объективно определялись признаки очень тяжелой формы ГС: воспалительные узлы (более 10), абсцессы (более 5) в ягодичной и поясничной областях; множественные сообщающиеся свищевые ходы (более 5), большое ко-

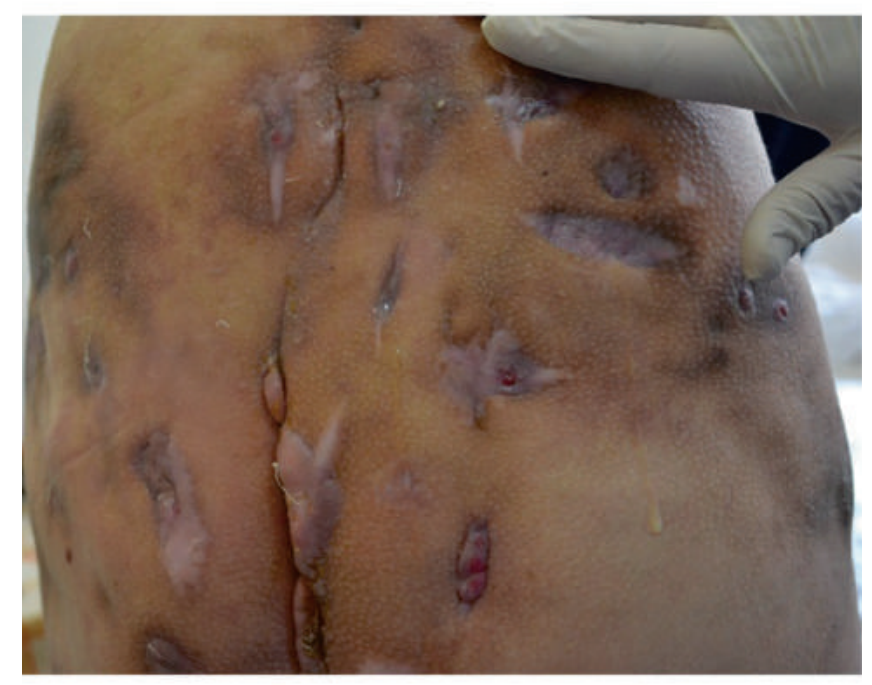

Рис. 7. Пациент К. Проявления ГС на коже ягодичной области

(воспалительные узлы, при надавливании на которые выделяется жидкое гнойно-кровянистое содержимое; абсцессы, постоперационные, гипертрофические и келоидные рубцы)

личество гнойного и гнойно-кровянистого отделяемого с неприятным запахом из свищевых отверстий, многочисленные рубцы. По индексу PGA это оценивалось как крайне тяжелая форма, по клинической классификации Hurley - III стадия. Пациент получал антибактериальную терапию (антибиотик цесралоспоринового ряда внутривенно капельно в течение 14 дней) с непродолжительным положительным эффектом. По данным бактериологического исследования, проведенного в мае 2016 г., в отделяемом свищевых ходов патогенной микрофрлоры не обнаружено. Проведенная в мае 2016 г. микробиологическая диагностика позволила исключить актиномикоз.

Учитывая крайне тяжелое течение основного заболевания - инверсные акне; гнойный (суппуративный)
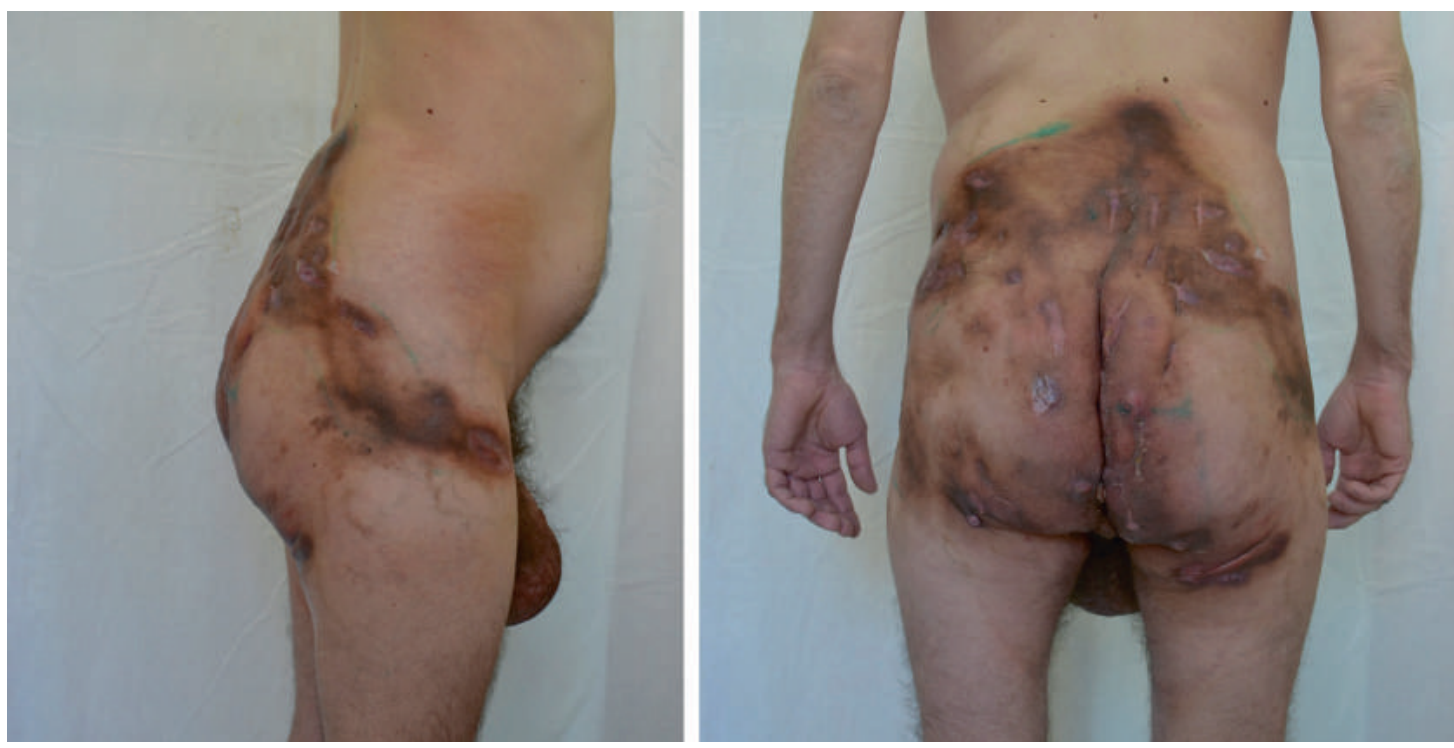


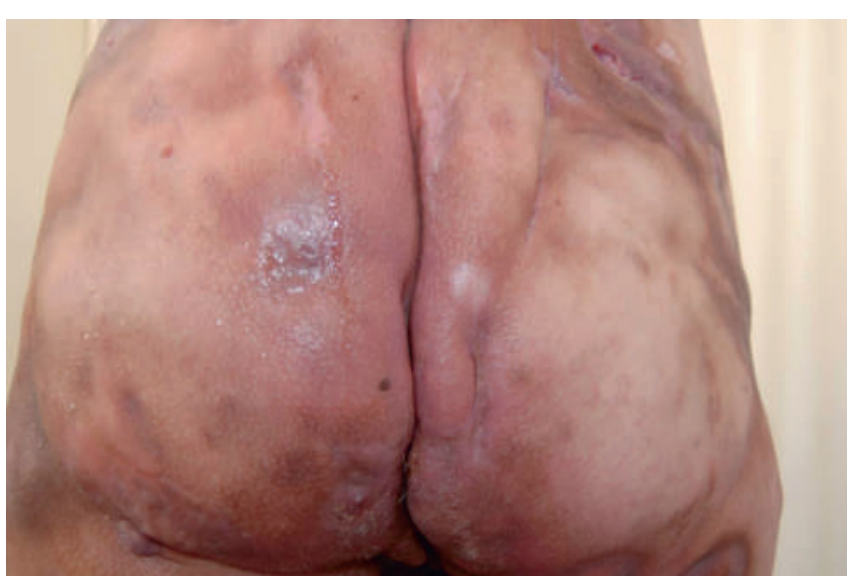

Рис. 9. Пациент К. Проявления ГС на коже ягодичной области (3 нед терапии адалимумабом)

гидраденит (сопутствующие заболевания: гидроцеле двусторонний осумкованный; железодефицитная анемия; поверхностный гастрит, вне обострения; хронический бронхит, вне обострения), отсутствие адекватного ответа на предшествующую стандартную системную терапию, отсутствие противопоказаний для терапии генно-инженерным биологическим препаратом, пациенту в мае 2016 г. был назначен генно-инженерный биологический препарат - адалимумаб $\left(\right.$ Хумира $\left.{ }^{\circledR}\right)$ по рекомендованной для этого заболевания схеме. Через 2 нед от начала терапии адалимумабом на фроне улучшения общего состояния (снижение температуры тела, улучшение лабораторных параметров крови) стал возможным этапный перевод па-

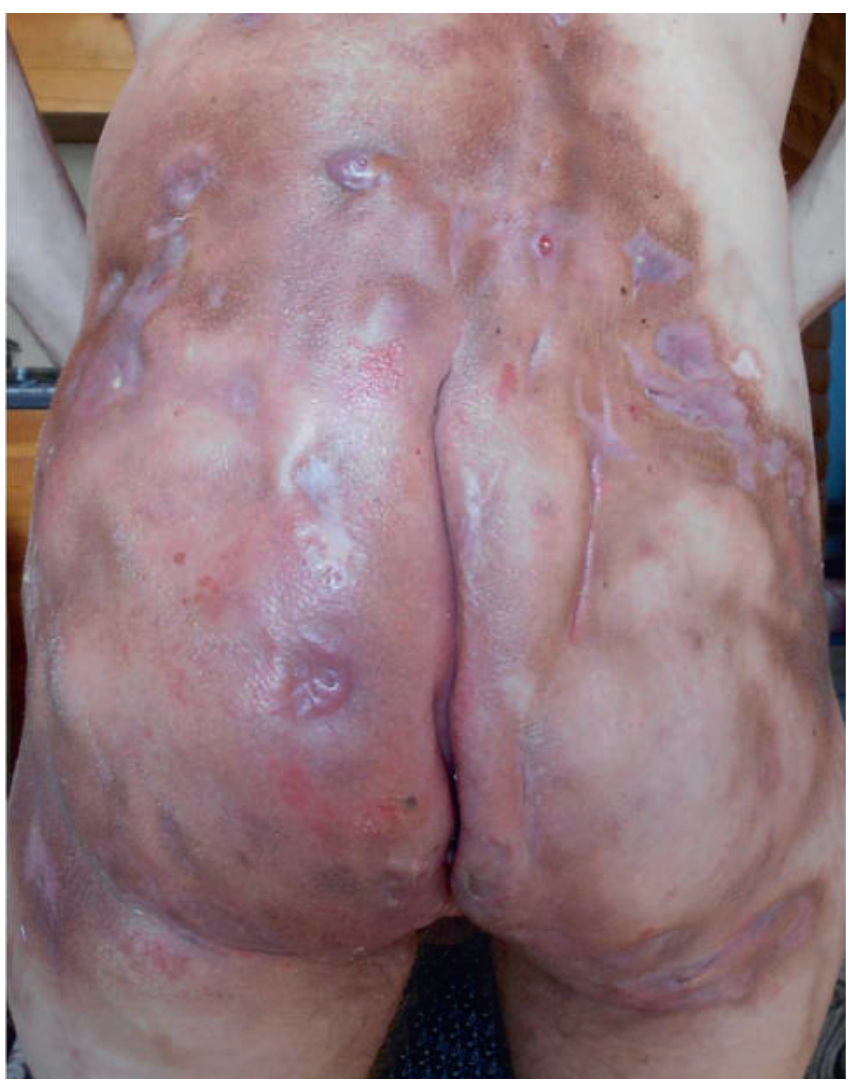

Рис. 10. Пациент К. Проявления ГС на коже поясничной и ягодичной областей (3 мес терапии адалимумабом) циента в хирургическое отделение, где он был оперирован по поводу гидроцеле двустороннего осумкованного (выполнена операция Бергмана). Послеоперационный период прошел без осложнений; ухудшения в течении основного заболевания не было (рис. 9).

С 29-го дня от начала применения адалимумаба осуществлялась поддерживающая терапия этим препаратом (по 40 мг 1 раз в неделю), которую пациент проводил по месту жительства. Со слов больного, на фроне терапии этим препаратом отмечалась выраженная положительная динамика: улучшалось общее состояние (уменьшились боли в области пораженных участков кожи, нормализовалась температура, уменьшилась слабость, отмечалось улучшение аппетита и увеличение массы тела), определялось разрешение существующих элементов кожного поражения, отсутствие появления новых (рис. 10). В июле 2016 г. в связи с эпизодическим подъемом температуры, увеличением гнойного отделяемого из 2 свищевых ходов была проведена, дополнительно к адалимумабу, 2-недельная антибактериальная терапия, которая купировала обострение.

В ноябре 2016 г. больной был вновь госпитализирован в клинику дерматовенерологии ПСПбГМУ им. акад. И. П. Павлова для оценки состояния, определения эфрективности и переносимости назначенной терапии. Объективно: поражение кожи носило ограниченный характер, было локализовано в ягодичной и поясничной областях; представлено воспалительными узлами (менее 3), абсцессами (менее 3). Из 2 свищевых отверстий выделялось небольшое количество жидкого гнойного и гнойно-кровянистого отделяемого. Определялись множественные гипертрофические рубцы, «закрытые» свищевые ходы. По шкале HiSCR терапию адалимумабом, проводимую в течение 6 мес, расценили как эфффективную. Количество абсцессов, воспалительных узлов, свищей на фоне терапии адалимумабом уменьшилось более чем на $60 \%$ (рис. 11, 12). Значительно улучшилось общее состояние пациента, его качество жизни. Подобной положительной динамики не наблюдали ранее, на предшествующих ва-

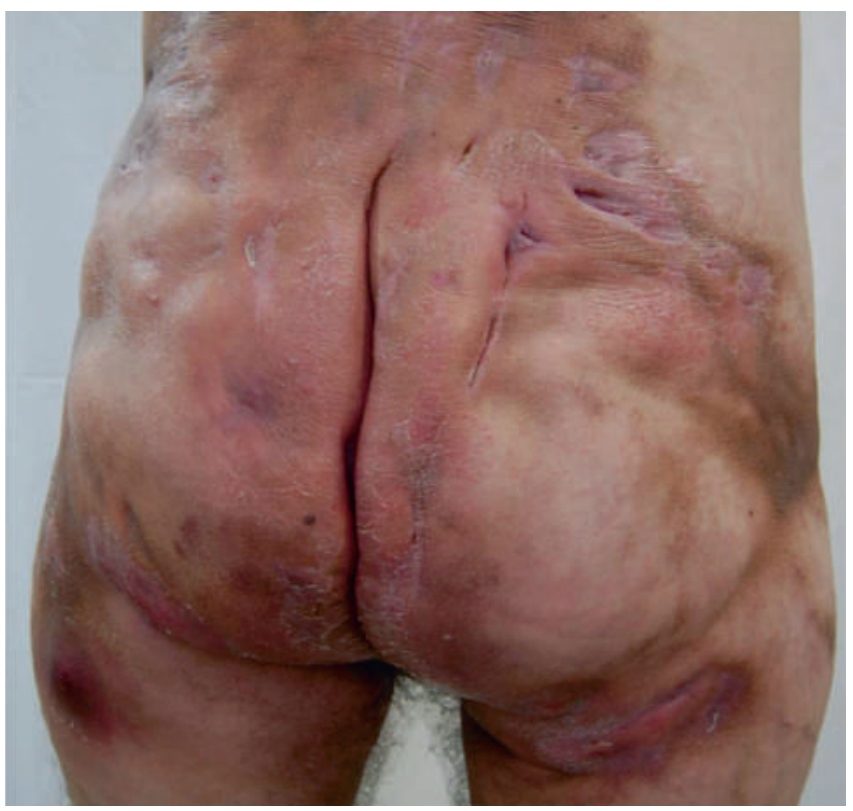

Рис. 11. Пациент К. Проявления разрешающегося ГС на коже поясничной и ягодичной областей (6 мес терапии адалимумабом) 
риантах терапии. При этом отмечалась нормализация лабораторных параметров (уменьшились лейкоцитоз, анемия, снизились острофразовые показатели (СОЭ, СРБ)). Результаты микроскопического исследования отделяемого свищевых ходов от ноября 2016 г.: эритроциты до 20 в поле зрения; клеток микроорганизмов не обнаружено. Результаты посева отделяемого свищевых ходов на флору и чувствительность к антибиотикам от ноября 2016 г.: роста фрлоры нет.

Переносимость терапии адалимумабом (Хумирой $\left.{ }^{\circledR}\right)$ у пациента была хорошей, нежелательных явлений не наблюдали. Противопоказаний для продолжения терапии генно-инженерным биологическим препаратом не было. Пациенту было рекомендовано продолжить лечение адалимумабом по схеме поддерживающей терапии.

\section{Заключение}

Современные представления о патогенезе ГС позволяют рассматривать его как разновидность инверсных акне, так как патогенез этих заболеваний не различается. Воспалительный процесс при ГС исходит не из апокриновых потовых желез, как это было принято считать ранее, а из расположенных также перифолликулярно сальных желез и является следствием первичного гиперкератоза в терминальных волосяных фолликулах с их окклюзией при гиперсекреции сальных желез. В последующем присоединяется бактериальное инфицирование резидентной микробной флорой, развивается иммунный ответ, что в итоге приводит к развитию клинических проявлений ГС. Суппуративный гидраденит представляет собой многофракториальное заболевание, при котором генетические, иммунные, эндокринные и поведенческие фракторы играют ключевую роль.

Детальные исследования пациентов с ГС, проведенные в последние годы, дали возможность предположить, что он является системным хроническим иммуноопосредованным прогрессирующим заболеванием. Доказано, что провоспалительный цитокин ФНО- $а$ играет ключевую роль в развитии воспалительного процесса при ГС. Повышенные уровни ФНО- $\alpha$ обнаружены в крови и в очагах поражения ГС, определяется положительная корреляция уровня ФНО- $\alpha$ с тяжестью болезни. ФНО- $\alpha$ увеличивает число молекул адгезии, что ведет к миграции лейкоцитов и способствует пролиферации эпителия, приводя к окклюзии фолликулов и риску их разрывов. Доказана роль ФНО- $\alpha$ в развитии хронического воспаления: поврежденные клетки сальной железы инициируют формирование абсцесса; ФНО- $\alpha$ и другие провоспалительные цитокины провоцируют изменения, вызывающие образование и пролифрерацию эпителизированных свищевых ходов; «биопленка» из бактерий, находящихся в поврежденных клетках и свищевых ходах, обеспечивает хронизацию воспаления, риск его распространения и развития обострений заболевания.

Поражение разных частей тела и неспецифические симптомы заставляют пациентов обращаться к врачам различных специальностей, которые в большинстве случаев принимают кожные поражения ГС за обычные абсцессы, в связи с чем постановка правильного диагноза ГС бывает значительно отсрочена. Представленный клинический случай подтверждает тот факт, что для пациентов с ГС очень важно максимально быстрое определение правильного диагноза и назначение рационального лечения в соответствии с разработанными рекомендациями. Ошибочные диагнозы, неадекватная терапия (хирургическое лечение, короткие курсы приема антибиотиков и т.д.) способствуют прогрессированию заболевания (развитию новых узлов, абсцессов; сложноразветвленных свищевых ходов, в просвете которых часто формируются грануляционно-рубцовые ткани, препятствующие разрешению этих элементов в последующем), появлению общих симптомов за счет присоединения вторичной инфекции и повышению общей интоксикации, ограничению работоспособности, формированию стойких и грубых рубцов, деформаций пораженных участков кожи.

Согласно модифрицированному алгоритму лечения ГС/инверсных акне, основанному на Европейском руководстве по лечению суппуративного гидраденита/инверсных акне 2015 г., при отсутствии адекватного ответа на стандартную системную терапию в случае активного ГС средней или тяжелой степени тяжести рекомендовано лечение блокатором ФНО- $\alpha$ - адалимумабом, единственным на сегодняшний день генно-инженерным био-

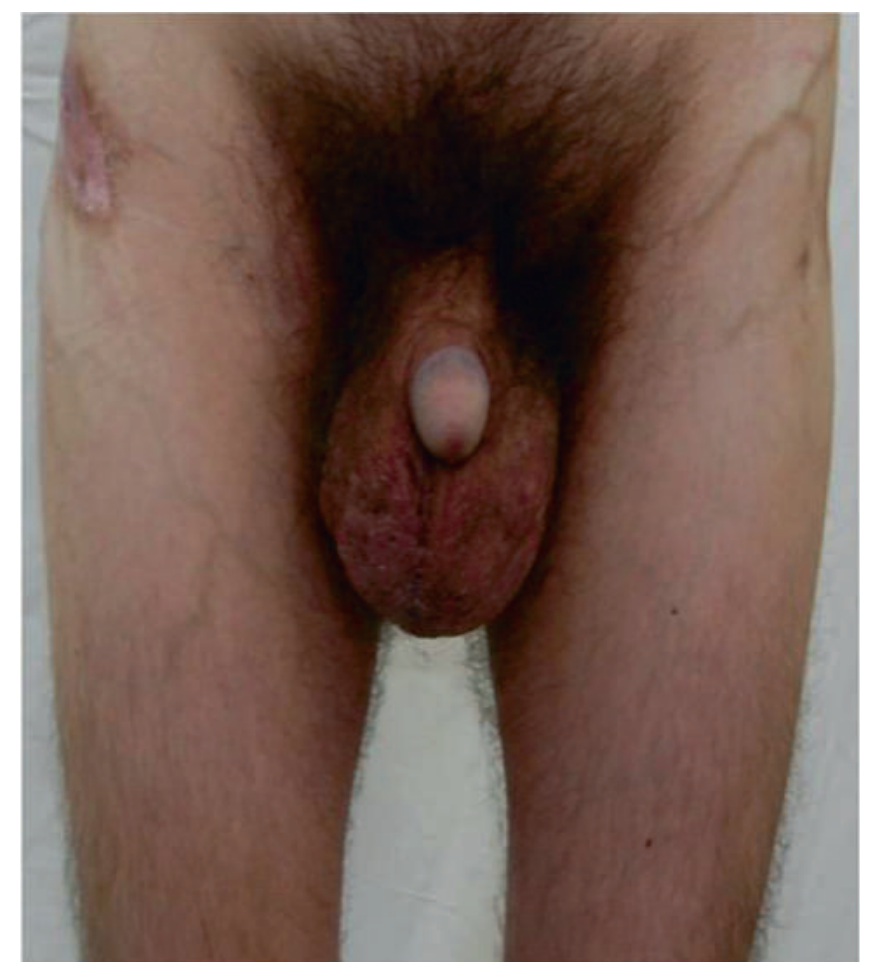

Рис. 12. Пациент К. Проявления разрешившегося ГС в пахово-мошоночной области (6 мес терапии адалимумабом, 5 мес после операции Бергмана по поводу двустороннего гидроцеле осумкованного)

логическим препаратом, одобренным для лечения ГС/ инверсных акне в мире и в России. Накоплен позитивный международный опыт его применения по данному показанию. Наш клинический случай применения этого препарата у пациента с крайне тяжелой формой ГС показал, что лечение адалимумабом (Хумирой $\left.{ }^{\circledR}\right)$ можетбыть эфрфективным и хорошо переносимым.

Безусловно, применение генно-инженерных биологических препаратов, в том числе адалимумаба, для лечения пациентов с ГС требует дальнейших исследований и наблюдений. Однако несомненно, что это новая перспективная возможность оптимизировать терапию самых тяжелых пациентов с этим заболеванием. 


\section{Литература/References}

1. van der Zee H. H., Laman J. D., Boer J., Prens E. P. Hidradenitis Suppurativa: Viewpoint on Clinical Phenotyping, Pathogenesis and Novel Treatments. Exp. Dermatol. 2012;21(10):735-739.

2. Jemec G. B. Clinical Practice: Hidradenitis Suppurativa. N. Engl. J. Med. 2012;366(2):158-164.

3. Михеев Г. Н., Аравийская Е. Р., Соколовский Е. В., Холодилова Н. А. Инверсные акне: современные представления о патогенезе, клинических проявлениях и терапии. Пластическая хирургия и косметология. 2010;(3):433-438. [Mikheev G. N., Araviiskaya E. R., Sokolovskiy E. V., Kholodilova N. A. Inverse Acne: Modern Concepts of Pathogenesis, Clinical Manifestations and Therapy. Plastic Surgery and Cosmetology. 2010;(3):433-438.]

4. Poli F., Jemec G. B., Revuz J. Clinical Presentation. In: Hidradenitis Suppurativa. Ed. by G. B. Jemec, J. Revuz, J. J. Leyden. Heidelberg: Springer-Verlag, 2006. P. 11-24.

5. van der Zee H. H., de Ruiter L., van den Broecke D. G. et al. Elevated Levels of Tumour Necrosis Factor (TNF)- $\alpha$, Interleukin (IL)- $1 \beta$ and IL-10 in Hidradenitis Suppurativa Skin: a Rationale for Targeting TNF- $\alpha$ and IL-1ß. Br. J. Dermatol. 2011;164(6):1292-1298.

6. Giamarellos-Bourboulis E. J., Antonopoulou A., Petropoulou C. et al. Altered Innate and Adaptive Immune Responses in Patients with Hidradenitis Suppurativa. Br. J. Dermatol. 2007;156(1):51-56.

7. Napolitano M., Megna M., Timoshchuk E. A. et al. Hidradenitis Suppurativa: from Pathogenesis to Diagnosis and Treatment. Clin., Cosmet. Investig. Dermatol. 2017;10:105-115.

8. Collier F., Smith R. C., Morton C. A. Diagnosis and Management of Hidradenitis Suppurativa. BMJ. 2013;346:\{2121.

9. Matusiak L., Bieniek A., Szepietowski J. C. Increased Serum Tumour Necrosis Factor-Alpha in Hidradenitis Suppurativa Patients: is There a Basis for Treatment with Anti-Tumour Necrosis Factor-Alpha Agents? Acta Derm. Venereol. 2009;89(6):601-603.

10. Mozeika E., Pilmane M., Nürnberg B. M., Jemec G. B. Tumour Necrosis Factor-Alpha and Matrix Metalloproteinase-2 are Expressed Strongly in Hidradenitis Suppurativa. Acta Derm. Venereol. 2013;93(3):301-304.

11. Humira (Summary of Product Characteristics). AbbVie Ltd., 2015.

12. Nazary M., van der Zee H. H., Prens E. P. et al. Pathogenesis and Pharmacotherapy of hidratenitis Suppurativa. Eur. J. Pharmacol. 2011;672(13):1-8.

13. Weller R., Hunter J., Savin J. et al. The Function and Structure of the Skin. In: Clinical Dermatology. Ed. by M. Sugden, R. Blundell. $4^{\text {th }}$ ed. Malden, MA: Blackwell Publishing, Inc., 2008. P. 10-33.

14. Fitzsimmons J. S., Guilbert P. R. A Family Study of Hidradenitis Suppurativa. J. Med. Genet. 1985;22(5):367-373.

15. Pink A. E., Simpson M. A., Desai N. et al. Mutations in the $\gamma$-Secretase Genes NCSTN, PSENEN, and PSEN1 Underlie Rare Forms of Hidradenitis Suppurativa (Acne Inversa). J. Invest. Dermatol. 2012;132(10):2459-2461

16. Jemec G. B., Heidenheim M., Nielsen N. H. The Prevalence of Hidradenitis Suppurativa and Its Potential Precursor Lesions. J. Am. Acad. Dermatol. 1996;35(2 Pt 1):191-194.
17. Revuz J. E., Canoui-Poitrine F., Pier Wolkenstein et al. Prevalence and Factors Associated with Hidradenitis Suppurativa: Results from Two Case-Control Studies. J. Am. Acad. Dermatol. 2008;59(4):596-601.

18. Jemec G. B. The Symptomatology of Hidradenitis Suppurativa in Women. Br. J. Dermatol. 1988;119(3):345-350.

19. Vazquez B. G., Alikhan A., Weaver A. L. et al. Incidence of Hidradenitis Suppurativa and Associated Factors: a Population-Based Study of Olmsted County, Minnesota. J. Invest. Dermatol. 2013;133(1):97-103.

20. Cosmatos I., Matcho A., Weinstein R. et al. Analysis of Patient Claims Data to Determine the Prevalence of Hidradenitis Suppurativa in the United States. J. Am. Acad. Dermatol. 2013;68(3):412-419.

21. Onderdijk A. J., van der Zee H. H., Esmann S. et al. Depression in Patients with Hidradenitis Suppurativa. J. Eur. Acad. Dermatol. Venereol. 2013;27(4):473-478.

22. Matuziak L., Bieniek A., Szipietowski J. C. Psychophysical Aspects of Hidradenitis Suppurativa. Acta Derm. Venereol. 2010;90(3):264-268.

23. Dufour D. N., Emtestam L., Jemec G. B. Hidradenitis Suppurativa: a Common and Burdensome, Yet Under Recognised Inflammatory Skin Disease. Postgrad. Med. J. 2014;90(1062):216-221.

24. Margesson L. J., Danby F. W. Hidradenitis Suppurativa. Best Pract. Res. Clin. Obstet. Gynaecol. 2014;28(7):1013-1027.

25. Zouboulis C. C., Desai N., Emtestam L. et al. European S1 Guideline for the Treatment of Hidradenitis Suppurativa/Acne Inversa. J. Eur. Acad. Dermatol. Venereol. 2015;29(4):619-644.

26. Kimball A., Jemec G. B., Gu Y. et al. A Novel Hidradenitis Suppurativa Efficacy Variable, HiSCR (Hidradenitis Suppurativa Clinical Response), is Responsive to Change with Adalimumab Therapy: Results of a Phase 2 Study. Paper presented at: $71^{\text {st }}$ Annual Meeting of the American Academy of Dermatology; March 1-5, 2013; Miami Beach, FL.

27. Wortsman X., Jemec G. B. A 3D Ultrasound Study of Sinus Tract Formation in Hidradenitis Suppurativa. Dermatol. Online J. 2013;19(6):18564.

28. Jemec G. B., Revuz J. Treatment. In: Hidradenitis Suppurativa. Ed. by G. B. Jemec, J. Revuz, J. L. Leyden. Germany: Springer, 2006. P. 183-186.

29. Kimball A. B., Jemec G. B., Yang M. et al. Assessing the Validity, Responsiveness and Meaningfulness of the Hidradenitis Suppurativa Clinical Response (HiSCR) as the Clinical Endpoint for Hidradenitis Suppurativa Treatment. Br. J. Dermatol. 2014;171(6):1434-1442.

30. Shah N. Hidradenitis Suppurativa: a Treatment Challenge. Am. Fam. Physician. 2005;72(8):1547-1552.

31. van der Zee H. H., Prens E. P., Boer J. Deroofing: a TissueSaving Surgical Technique for the Treatment of Mild to Moderate Hidradenitis Suppurativa Lesions. J. Am. Acad. Dermatol. 2010;63(3):475-480.

32. Alharbi Z., Kauczok J., Pallua N. A Review of Wide Surgical Excision of Hidradenitis Suppurativa. BMC Dermatol. 2012;12:9.

33. Gulliver W., Zouboulis C. C., Prens E. et al. Evidence-Based Approach to the Treatment of Hidradenitis Suppurativa/Acne Inversa, Based on the European Guidelines for Hidradenitis Suppurativa. Rev. Endocr. Metab. Disord. 2016;17(3):343-351. 
81 - № 5, 2017

34. Kimball A. B., Jemec G., Armstrong A. et al. Evaluating Optimal Medium-Term Dosing Strategy for Adalimumab in Patients with Moderate-toSevere Hidradenitis Suppurativa Based on Analysis of Integrated Results from the PIONEER I \& II Phase 3, Randomized, Placebo-Controlled Trials. Poster presented at: 23 $3^{\text {rd }}$ World Congress of Dermatology (WCD); June 8-13, 2014; Vancouver, Canada. Abstract 3079375.

35. Kimball A. B., Zouboulis C. C., Armstrong A. W. et al. Safety and Efficacy of Adalimumab in Patients with Moderate to Severe Hidradenitis Suppurativa: Results from First 12 Weeks of PIONEER I, a Phase 3, Randomized, Placebo-Controlled Trial. Paper presented at: $73^{\text {rd }}$ Annual
Meeting of the American Academy of Dermatology; March 20-24, 2015; San Francisco, CA.

36. Jemec G. B., Gottlieb A., Forman S. et al. Efficacy and Safety of Adalimumab in Patients with Moderate to Severe Hidradenitis Suppurativa: Results from PIONEER II, a Phase 3 Randomized Placebo-Controlled Trial. Paper presented at: $73^{\text {rd }}$ Annual Meeting of the American Academy of Dermatology; March 20-24, 2015; San Francisco, CA.

37. Инструкция по применению препарата Хумира от 12.05.2016. 49 c. [Instructions for the Use of the Drug Humira from 05.12.2016. 49 p.]

\section{Информация об авторах}

Марианна Михайловна Хобейш - к.м.Н., доцент кафедры дерматовенерологии с клиникой, Первый Санкт-Петербургский государственный медицинский университет им. акад. И. П. Павлова Минздрава России; e-mail: mkhobeysh@yandex.ru

Денис Вадимович Шустов - врач клиники дерматовенерологии, Первый Санкт-Петербургский государственный медицинский университет им. акад. И. П. Павлова Минздрава России

Евгений Владиславович Соколовский - д.м.н., профрессор, заведующий кафедрой дерматовенерологии с клиникой, Первый Санкт-Петербургский государственный медицинский университет им. акад. И.П. Павлова Минздрава России 